\title{
LO OCULTO Y LAS TERAPÉUTICAS ESPIRITISTAS DEL ESPÍRITU Y DEL CUERPO EN FRANCIA (1850-1914): DE LA CREENCIA AL SABER Y VUELTA*
}

\author{
Nicole Edelman
}

Université Paris X

\begin{abstract}
RESUMEN
En el período estudiado el espiritismo se desarrolla en Francia con un gran vigor. En su seno surge, desde el primer momento, una «medicina espiritista», heredera del precedente magnetismo animal, que se pone en práctica a través del sujeto/objeto de las experiencias espiritistas: el/la médium. Una característica de esta medicina es la sistemática apropiación de los descubrimientos realizados por las ciencias socialmente reconocidas, especialmente la medicina académica y la física, a menudo en franco conflicto con estas mismas ciencias. Se señalan las correspondencias entre el discurso espiritista y el espiritualista en sus dos versiones principales en ese momento (la religión y los trabajos de las Societies for Psychical Research anglosajonas) y se muestran los conflictos entre la doctrina espiritista y los desarrollos contemporáneos de la psicología experimental, la neurología clínica y el psicoanálisis.
\end{abstract}

PALABRAS CLAVE: Espiritismo, medicina, psicología, religión, milagro, posesión.

\begin{abstract}
In the period examined, spiritualism developed in France with great vigour. From the very start, a "spiritualist medicine" arose -heir to its precedent, mesmerism, which was put into practice through the subject/object of spiritualistic experiences: the medium. A characteristic of this medicine is the systematic appropriation of the discoveries made by the socially recognised sciences, particularly academic medicine and physics, although often in direct conflict with these same sciences. The relationships between the spiritualistic discourse and the spiritualist in their two principal versions at the time (religion and the works of the Anglo-Saxon Societies for Psychical Research) are noted, and conflicts between spiritualist doctrine and the contemporary developments of experimental psychology, clinical neurology and psychoanalysis are shown.
\end{abstract}

KEY WORDS: Spiritualism, medicine, psychology, religion, miracle, possession.

* Traducción de Luis Montiel. 
Las fronteras epistemológicas que separan lo oculto de lo que sería la ciencia fluctúan no solamente según los momentos de la historia, sino también según los actores o los autores que las definen ${ }^{1}$. Lo oculto y la medicina se han entrecruzado a menudo, y el espiritismo fue uno de los espacios más duraderos de este encuentro. Esta religión que se dice científica tuvo desde su nacimiento en 1857 una «medicina espiritista» que se apoyaba sobre una interpretación del cuerpo humano, de su estructura, de su salud y de sus males. Estaba anclada en concepciones teóricas y prácticas anteriores, en particular en las del magnetismo animal, las del sonambulismo magnético y, luego, las de la hipnosis. Estos saberes y estas prácticas se actualizaron constantemente en función de los descubrimientos médicos. Los últimos decenios del siglo XIX se caracterizan por una excepcional floración de la prensa ocultista: revistas y periódicos teosóficos, magnéticos y espiritistas en particular, así como por la proliferación de lugares de reunión: salones, sociedades científicas ${ }^{2}$, incluso congresos médicos, donde se dan cita psiquiatras, neurólogos y psicólogos que trabajan sobre la hipnosis, las enfermedades mentales y nerviosas, y espiritistas cuya ambición es promover una nueva ciencia psíquica.

\section{LOS ORÍGENES: UNA NUEVA CONCEPCIÓN DEL HOMBRE.}

El fundador de esta nueva religión, Allan Kardec —seudónimo de Hippolyte Léon Denizard Rivail (1804-1869), profesor de enseñanza secundaria, gran lector, curioso y apasionado por las ciencias de su época- se sintió intrigado por los movimientos de las «mesas giratorias», moda procedente de los Estados Unidos llegada a Europa en $1853^{3}$. En un primer momento investigó las causas puramente físicas o fisiológicas del fenómeno: electricidad, dilatación de la madera, energía mecánica, movimientos inconscientes... Luego, estimando que las mesas respondían inteligentemente a las preguntas formuladas haciendo sonar golpes según un orden preestablecido, dedujo que se trataba de algo muy diferente. En efecto, esas cosas misteriosas se identifican:

1 Cfr. Lagrange, P.; D’Andrea, P. (2002). «Définitions occultes», en: BensaudeVincent, B.; Blondel, Ch.. (Dirs.) Des savants face à l'occulte 1870-1940. Paris, La Découverte, pp. 19-39.

2 «Sociétés savantes» en el original. Se trata de una particularidad francesa que no se corresponde exactamente con lo que entre nosotros se denomina «sociedad científica»; pero no conozco una traducción exacta para este término (N. del T.)

3 Cfr. Conan Doyle, A. (1981). Histoire du spiritisme. Paris, Ed. Du Rocher, cap. 4-7. ( $1^{\text {a }}$ ed. inglesa, 1926-1927). 
son Espíritus; y esos seres invisibles indican muy pronto otros medios más rápidos y más eficaces de comunicación. Se apoderan de las manos de personas dotadas, en adelante llamadas médiums, para transmitir comunicaciones escritas, método que los surrealistas denominarán «escritura automática» algunas décadas más tarde.

El propio Kardec, no siendo médium, trabaja con personas que lo son. Primero se trata de mujeres que han practicado el sonambulismo magnético, y en ese estado de conciencia modificado van a responder a las preguntas muy precisas que Kardec les formula ${ }^{4}$. Pero para los espiritistas el sonambulismo y la condición de médium no son de la misma naturaleza. «El sonámbulo actúa bajo la influencia de su propio Espíritu: es su alma quien, en los momentos de emancipación, ve, oye y percibe más allá de los límites de sus sentidos (...) El médium, por el contrario, es el instrumento de una inteligencia ajena» ${ }^{5}$. De este modo se elabora, en algunos años, la «Biblia» de los espiritistas: Le livre des Esprits, publicado en 1857. Tiene la estructura de un catecismo, compuesto esencialmente por preguntas formuladas por Kardec a los Espíritus y por las respuestas dadas por las sonámbulas con las que aquél trabajó.

El espiritismo se presenta como una nueva revelación, la tercera después de la de Moisés y la de Jesús, adaptada a los tiempos modernos de la ciencia y con un carácter doble, pues «tiene a la vez una parte de revelación divina y otra de revelación científica» ${ }^{6}$; divina por su carácter providencial, ya que no depende de una iniciativa humana, y científica porque la doctrina «se deduce a partir del trabajo del hombre, de la observación de los hechos (...) El espiritismo procede exactamente de la misma manera que las ciencias positivas, es decir, aplica el método experimental» ${ }^{7}$, pero... a las cosas metafísicas. Por esta vía, los espiritistas colisionan de lleno con las concepciones dominantes del positivismo y del cientismo, que se oponen a la investigación de semejantes causas primeras. Ahora bien: los espiritistas llevan a cabo experiencias que no sólo les conducen a ese tipo de causalidad; aún más, toman por hipótesis de trabajo esas causas primeras, a saber, la existencia de entidades extraterrestres procedentes de lo divino, los Espíritus. Para estos espiritualistas, la ciencia materialista, la de los científicos alemanes en particular, pero también

4 Edelman, N. (1995). Voyantes, guérisseuses et visionnaires en France, 1785-1914. Paris, Albin Michel.

5 Kardec, A. (1984 a). Le Livre des Médiums. Paris, Dervy, p. 208. (1 ${ }^{\text {a }}$ ed. Paris, Didier, 1861).

6 KARDEC, A. (1952). La genèse, les miracles et les prédictions selon le spiritisme. Paris, La Diffusion scientifique, p. 13. ( $1^{\text {a }}$ ed. 1868).

7 Ibid. 
la de un Littré, es una ciencia prostituída que da de lado a lo esencial. La escritura «automática» y los movimientos de objetos no se consideran experiencias susceptibles de aportar pruebas sobre la existencia de estos hechos, sino que son la prueba de la existencia de los espíritus. Las mesas, las tablillas y luego la mano del médium espiritista se mueven porque los espíritus existen. Así, para Kardec no se trata de una hipótesis de partida según la cual los espiritistas habrían imaginado a los espíritus como medio de explicar los fenómenos. Al contrario, es el fenómeno mismo, la mesa que habla, quien revela la palabra, espíritu. «En las ciencias exactas - escribe Kardec - se plantean a menudo hipótesis para tener una base para el razonamiento; pero aquí no es ese el caso, en absoluto $\rangle^{8}$. A partir de aquí, para los espiritistas, la existencia de los espíritus es irrefutable, es la Verdad porque está demostrada; no necesita de la fe, como el catolicismo. La tablilla o la mano del médium son capaces de escribir textos que tienen sentido porque son movidas por los espíritus. No existe otra explicación racional posible tan sencilla y evidente para estos fenómenos.

El espiritismo propone una interpretación del mundo y de los hombres. Para comenzar, el universo está regido por dos fuerzas: «el elemento espiritual y el elemento material; de la acción simultánea de estos dos principios nacen fenómenos especiales que son naturalmente inexplicables si se hace abstracción de uno de ellos (...). El espiritismo, al demostrar la existencia del mundo espiritual y sus relaciones con el mundo material da la clave de una multitud de fenómenos incomprendidos y considerados por eso mismo como inadmisibles por una cierta clase de pensadores» ${ }^{9}$. El mundo está poblado de «Espíritus», de los que algunos pueden vivir en la tierra, pero también en muchos otros lugares. Estos Espíritus constituyen el mundo espiritual, el único importante. El mundo corporal es, en efecto, secundario. El planeta Tierra es un lugar entre millones de otros, mal situado en la jerarquía de los Espíritus, que son en efecto desiguales: los más elevados son los ángeles o espíritus puros, los más cercanos a lo divino, desprovistos de toda materialidad y, en consecuencia, ajenos a una vida en planeta alguno. Sin embargo, cualquiera que sea su nivel de partida, todo Espíritu progresa gracias a encarnaciones sucesivas. Así, Dios ha elegido la tierra y la especie humana para la encarnación de espíritus llegados a un cierto grado de desarrollo. El Espíritu puede reencarnarse sea porque debe expiar faltas cometidas en vidas anteriores, sea porque ha sido enviado en misión para ayudar a los precedentes a hacerse mejores.

8 KARdec, A. (1984 b) Le Livre des Esprits. Paris, Dervy, p. VII (1 ${ }^{\mathrm{a}}$ ed. 1857).

9 KARDEC, A. (1952), p. 7 
En cuanto al hombre, está formado por tres elementos: el primero es «el cuerpo o ser material análogo a los animales ${ }^{10} \mathrm{y}$ animado por el mismo principio vital» ${ }^{11}$ que tiene su fuente en el fluido universal o magnético. Kardec conoce, como la mayor parte de sus contemporáneos, el magnetismo animal, su práctica y sus fundamentos teóricos, así como el sonambulismo magnético, que es para él un estado diferente de la condición de médium, siendo ésta la única que permite una relación con los espíritus. El segundo elemento es el alma o ser inmaterial, el espíritu encarnado en el cuerpo. Existe, por fin, un lazo entre el alma y el cuerpo: el periespíritu, una especie de envoltura semimaterial, gran invención del espiritismo y elemento nodal de su coherencia teórica.

Para los cuidados del cuerpo stricto sensu, la medicina espiritista se apoya esencialmente en las prácticas procedentes del magnetismo animal y sobre la convicción en que existe un fluido magnético: «la enfermedad es el resultado de numerosas alteraciones del fluido vital (Dr. Régnier)»12. El magnetismo es considerado como una ciencia de pleno derecho. Su acción terapéutica es, con la mayor frecuencia, atribuida a este fluido, un agente invisible que emana del cuerpo humano. En La Revue spirite, numerosos informes de experiencias dan cuenta de «la acción evidente de un principio que se despega del cuerpo del magnetizador y que influye a distancia a la persona sometida a la acción de este principio» ${ }^{13}$. En los años 80 del siglo XIX los espiritistas llaman la atención sobre los efectos benéficos del hipnotismo y conocen los trabajos de los médicos de Nancy Auguste Liebéault (1823-1904) e Hippolyte Bernheim (1840-1919), a quienes admiran porque difunden el conocimiento del magnetismo y sus beneficios terapéuticos. La reputación de la clínica del Dr. Liebéault, abierta en las afueras de Nancy, permitió en efecto curar por el sonambulismo magnético a un gran número de pacientes y hacer renacer estas prácticas que Bernheim descubrirá a su vez en 1882, introduciéndolas en su servicio hospitalario, donde desarrollará ampliamente experiencias sobre la hipnosis. Por otra parte, los espiritistas se permiten un amplio eclecticismo: vegetarianos a menudo, homeópatas, los lazos entre Mesmer y Hahnemann son subrayados frecuentemente ${ }^{14}$. Sin embargo, cierto número de cuidados son suministrados por no médicos, y para sortear las condenas por ejercicio

\footnotetext{
10 Según los espiritistas, un Espíritu no puede encarnarse en el cuerpo de un animal.

11 KARDEC, A. (1984 b), p. X.

12 Bulletin de la Société scientifique d'études psychologiques, 15, octobre 1886.

13 Revue spirite. Journal d'études psychologiques, mars 1880, p. 205.

14 El periódico La chaîne magnétique, creado en 1879, dice titularse así por existir una cadena que va «de Mesmer a Hannemann (sic)» juillet 1879 p. 15.
} 
ilegal de la medicina, algunos médiums, sobre todo mujeres, trabajan con médi$\cos u$ oficiales de salud que firman las prescripciones que les dictan sus colaboradoras ${ }^{15}$. Otros preconizan simplemente tratamientos sin medicamentos, arguyendo que «el magnetismo, el masaje y otras aplicaciones de ciencias similares constituyen un tratamiento natural y racional, sin aplicar ni prescribir remedios», tratamiento que tiene más que ver «con la fisiología y la psicología que con la patología», fórmula ésta que deja perplejo. Así, el 28 de marzo de 1893 se constituye en París un sindicato «de magnetizadores, masajistas, fascinadores, sugestionadores, médiums sanadores y cualesquiera otros que traten sin medicamentos ${ }^{16}$. La ley de 1892 , que tenía por objeto adaptar el encuadramiento del ejercicio de la medicina, había sido votada el año precedente, suprimiendo los oficiales de salud y no conservando más que un solo tipo de práctico: el doctor en medicina. A partir de este momento se emprendió una serie de persecuciones contra los magnetizadores, hipnotizadores, curanderos y otros charlatanes, lo que explica sin duda la creación de este curioso sindicato.

Sin embargo, si los espiritistas se interesan por el cuerpo de los hombres, por su parte orgánica y material, se preocupan sobre todo por las relaciones entre su espíritu y su cuerpo. Para ellos, la muerte no es sino la destrucción del cuerpo, envoltura grosera del Espíritu que conserva, sin embargo, el periespíritu a su disposición en el más allá. Esta envoltura fluídica es normalmente invisible para los hombres, pero el Espíritu puede hacerla visible excepcionalmente, e incluso tangible, si lo desea. Esta capacidad explica el fenómeno de las apariciones. Este nexo entre el cuerpo y el espíritu que es el periespíritu es, pues, esencial. Esta segunda envoltura existe durante la vida corporal: es «el intermediario de todas las sensaciones que percibe el Espíritu, aquello por lo que el Espíritu transmite su voluntad al exterior y actúa sobre los órganos: para servirnos de un símil material - escribe Kardec- es el hilo conductor eléctrico que sirve para la recepción y la transmisión del pensamiento. Es ese agente misterioso, intangible, designado con el nombre de fluido nervioso, que desempeña un papel tan grande en la economía y que aún no se tiene en cuenta en medida suficiente en los fenómenos fisiológicos y patológicos» ${ }^{17}$. Este periespíritu está compuesto por una materia extremadamente sutil, a la vez «fluídica» y material, y sus usos terapéuticos son, desde luego, numerosos,

Permite en particular resolver la cuestión fundamental del nexo entre espíritu y materia, ya que el espíritu se ve dotado de «atributos fisiológicos» bajo

15 Cfr. Edelman, N. (1995), pp. 54-59.

16 La chaîne magnétique, 15 sep. 1893, pp. 30-31.

17 KARDEC, A. (1984 a), p. 62. 
esta forma «fluídica», semejante a fenómenos eléctricos que recorren esos hilos conductores que son los nervios. De este modo el espiritismo puede presentarse como «la» nueva ciencia psíquica. Kardec utilizará el término «psíquico», aunque prefiere el de «psicológico». De hecho, titula Revue spirite. Journal d'études psychologiques la revista que funda en 1858. Como veremos, sus sucesores jugarán mucho con las palabras, usando a menudo el término «psicología experimental» a fin de poder participar en los congresos científicos del fin de siglo ${ }^{18}$. En efecto, en este momento, «el término consagrado, directamente traducido del inglés, para designar el estudio científico de los fenómenos paranormales era investigación(es) psiquica(s), y los espiritistas franceses lo sabían perfectamente» ${ }^{19}$.

Para fundar esta nueva ciencia psíquica o psicológica el espiritismo propone todo un conjunto de explicaciones extremadamente coherentes para todo tipo de fenómenos que tengan que ver con lo psíquico, y ofrece además múltiples terapéuticas.

En primer lugar, siendo el fluido universal el elemento primitivo del cuerpo carnal y del periespíritu, un Espíritu poderoso, encarnado o no, puede proporcionar al cuerpo principios reparadores. Es capaz de curar instantáneamente a un enfermo, y así es como se explican los milagros. Por otra parte, en el nivel de los seres humanos las lesiones dolorosas del cuerpo repercuten sobre el espíritu al modo de una descarga eléctrica mediante el fluido periespiritual del que los nervios son hilos conductores. A la inversa, si el espíritu moviliza todo el fluido corporal, el cuerpo se volverá insensible e incluso podrá entrar en catalepsia o en letargia. La parálisis, a cambio, tiene otras causas: los nervios dejan de ser aptos para permitir el paso del fluido. Un médium puede también hacer intervenir un Espíritu para prestar cuidados. Así pues, existe un género de condición de médium que consiste principalmente en el don que «algunas personas poseen de curar por simple contacto, por la mirada, incluso por un gesto, sin la ayuda de medicación alguna. Se dirá sin duda que esto no es otra cosa que magnetismo. Es evidente que el fluido magnético desempeña aquí un papel importante; pero cuando se examina este fenómeno con cuidado, se reconoce sin dificultad que hay algo más» ${ }^{20}$, a saber, la intervención de los Espíritus. Igualmente un buen Espíritu puede expulsar a uno malo: como

18 Cfr. Plas, R. (2000). Naissance d'une science humaine: la psychologie, les psychologies et le «merveilleux psychique». Rennes, Presse Universitaire de Rennes, pp. 34-42.

19 Ibid., p. 35. Las Societies for Psychical Research inglesas y estadounidenses se crean a comienzos de los años 1880.

20 KARDEC, A. (1984 a), p. 210. 
la obsesión y la posesión significan que un Espíritu malo se ha apoderado del cuerpo, la intervención de un buen Espíritu permitirá la expulsión del malvado. Un buen médium o un magnetizador podrá producir el mismo resultado. El sanador Jean Béziat, que intervino en el $2^{\circ}$ Congreso espiritista universal en 1913, declaraba: «Un día, una joven de Aubervilliers, Mlle. Marie C..., acudió absolutamente poseída por un mal espíritu que le obligaba a hacer excentricidades. M. Pillaut [su colaborador], logró, mediante exhortaciones, expulsar al mal espíritu que dominaba a esta infortunada $\rangle^{21}$. La obsesión o la posesión pueden ser también colectivas cuando una nube de malos Espíritus se abate sobre un pueblo o un lugar, lo que ocurrió, según los espiritistas, en Morzine. En la primavera de 1857 una epidemia de posesión se apoderó de este pueblecito saboyano, en aquella época aún sardo. Después de que fracasaran los exorcismos realizados por el cura, y a pesar de un relativo éxito del magnetizador Lafontaine, que había sido llamado por algunos lugareños, las autoridades francesas - pues Saboya se había reincorporado a Francia en 1860 - hicieron acudir a algunos alienistas que apenas consiguieron algo. Fue preciso esperar varios años para que el orden volviera ${ }^{22}$. Los espiritistas consideraron esos fracasos repetidos como pruebas de su aserto: los malos Espíritus se habían apoderado de los lugareños.

Y por fin, otra manera de curar: un médico espiritista podría, evocando a «aquellos de sus enfermos que han muerto, obtener informaciones sobre la causa de su muerte, los errores que hubiera podido cometer en el tratamiento, y adquirir así un incremento de experiencia (...) sobre todo si se hacía asistir por Espíritus ilustrados que suplirían la falta de conocimiento de algunos enfermos ${ }^{23}$.

El postulado que hace del espiritismo una nueva ciencia psíquica es concebible a finales de la década de 1860 cuando Kardec y los espiritistas lo formulan. En efecto, después de la condena del sonambulismo magnético en Francia a finales de los años 30, las investigaciones sobre la hipnosis no se reanudaron en un marco científico, incluso aunque numerosos médicos continuaran utilizando la hipnosis como terapéutica. Además la psicología, en tanto que ciencia humana, no había nacido aún. Por otra parte, los alienistas con-

21 2ème Congrès spirite universel, organise par le bureau international du spiritisme. Compte rendue sténographique, Genève, 1913, p. 117.

22 Cfr. CARroy-Thirard, J. (1981). Le mal de Morzine, de la possession à l'hystérie (1857-1873). Paris, Solin. Laurence-Maire, C. (1981). Les possédés de Morzines, 18571873. Lyon, PUL. Edelman, N. (2003). Les metamorphoses de l'histérique. Des le debut du XIXème siècle à la Grande Guerre. Paris, La Découverte, cap. 4: «Mal du diable», pp. 75-93.

23 KARDEC, A. (1954 a), p. 402. 
cebían mayoritariamente la locura en términos de enfermedad mental, que interpretaban de manera somaticista. El concepto de degeneración acababa de ver la luz con la publicación en 1857 del Traité des dégénérescences physiques, intellectuelles et morales de l'espèce humaine et des causes qui produisent ces variétés maladives ${ }^{24}$ de B.A. Morel (1809-1873), médico jefe del asilo de Saint-Yon. Este concepto de degeneración nació de un cuestionamiento del alienista respecto de una población obrera pobre que intentaba curar en el asilo a su cargo. Morel piensa que el hombre, herido ya por primera vez por el pecado original, puede en todo momento desviarse de su tipo primitivo o normal por una herencia morbosa. Llama a esto degeneración, cuyas causas, así como los medios de combatirla, son a la vez psíquicos, morales y sociales, siendo, para él, las clases más pobres las más susceptibles de padecerla. Sin embargo, al estar dotado de una sólida fe católica, no desespera de la humanidad, pues cree en la sabiduría divina.

En resumen: la llegada a Europa del fenómeno de las mesas giratorias en 1853, los de Morzine en 1857 y las apariciones de la Virgen María en Lourdes en 1858 traen al primer plano la cuestión de la porosidad de las fronteras entre lo natural y lo sobrenatural.

Pero veinte años más tarde estos conceptos van a refundarse sobre nuevas bases: los espiritistas va a apoyarse entonces a la vez sobre las experiencias y los resultados obtenidos en materia de investigaciones sobre los fenómenos ocultos por las Societies for Psychical Research inglesa y americana (que no son espiritistas), sobre los descubrimientos en psicología y en fisiología, que interpretan según sus propios postulados, y sobre la ciencia magnética, que siguen considerando reconocida.

Esta puesta al día teórica y práctica permite al espiritismo continuar pretendiendo ser «la» ciencia psíquica, y situarse de facto en total oposición a la psiquiatría, la psicología y el psicoanálisis. En 1896, la Revue spirite, al informar sobre un artículo de Jules Bois titulado «La nueva psicología», subraya el hecho de que las nuevas escuelas y doctrinas psicológicas son cada vez menos materialistas. Después de Charcot y Ribot y de la psicología fisiológica o patológica, han aparecido «los Liebéault, los Bernheim y los Bérillon», y «la hipnosis, y luego la sugestión, han inaugurado la 'psicoterapia' (...) una especie de tratamiento espiritual, un culto por la idea-fuerza, una atención y un homenaje creciente a las misteriosas influencias que deciden, mucho más que la química o la farmacia, sobre nuestro malestar y sobre nuestro bienes-

24 Morel, B.A. (1857). Traité des dégénérescences physiques, intellectuelles et morales de l'espèce humaine et des causes qui produisent ces variétés maladives. Paris, Baillière. 
tar». Y poco a poco, «los nuevos psicólogos no sólo se comprometen con nuestras miserias corporales o psicofisiológicas, sino que también han tocado, con mano prudente y feliz, el más allá de la muerte» ${ }^{25}$. Los espiritistas serían, pues, los poseedores de la nueva ciencia psicológica.

Así, a partir de los años 80 los espiritistas combaten violentamente a la vez contra la psiquiatría, la neurología y la psicología y sus terapéuticas médicas. No dejarán de intentar invalidarlas mediante una búsqueda constante de la existencia del periespíritu, y a través de una interpretación mediúmnica de la hipnosis fundada sobre el rechazo absoluto de la noción de inconsciente. Multiplican las experiencias con la ambición de demostrar la existencia de diferentes estados de la materia, de los cuales algunos serían aún desconocidos. En efecto, si la materia se presenta bajo muchas formas, sería posible explicar la existencia del periespíritu, pues esta envoltura fluídica del alma sería de orden material. Demostrar la realidad del periespíritu permitiría, de rebote, probar la sustancialidad del alma, la posibilidad de su reencarnación, la existencia de entidades extraterrestres y, en consecuencia, la posibilidad de cuidados diferentes de los suministrados por la medicina tradicional, psiquiátrica o no, y finalmente, invalidar la posibilidad de un yo dividido que las experiencias sobre sujetos en estado de hipnosis estaban poniendo sobre el pavés en los hospitales.

\section{ESPÍRITUS VERSUS INCONSCIENTE.}

Durante las últimas décadas del siglo XIX y la primera mitad del XX los espiritistas lucharán palmo a palmo contra el descubrimiento de un inconsciente como el que aflora en los trabajos sobre la hipnosis y... sobre la condición de médium. Oponen sistemáticamente sus interpretaciones a todos los fenómenos descubiertos en particular por los médicos Hippolyte Bernheim, Pierre Janet, Théodore Flournoy y Sigmund Freud. La hipnosis, estado de conciencia modificado cuyo origen y naturaleza se ignoran, es a la sazón uno de los fenómenos ocultos más conocidos por el gran público. Redescubierta en 1784 por el marqués de Puységur, denominada entonces «sonambulismo magnético», condenada luego en 1837 por una comisión procedente de instancias médicas reconocidas, no vuelve a encontrar un estatuto científico hasta que es observada en el medio hospitalario por médicos especialistas en enfermedades nerviosas, como Jean Martin Charcot (1825-1893) en la Salpê-

25 Revue spirite, mai 1896, p. 589. 
trière, quien hace de ella una «histeria experimental» en su comunicación a la prestigiosa Académie des Sciences en 1882, o como Jules Luys (1828-1897) en La Charité. Así, la hipnosis resurgía en el dominio médico y hospitalario, pero bajo una forma patológica.

Ahora bien, la condición de médium espiritista deriva en línea recta, como puede recordarse, del sonambulismo magnético, ya que los primeros médiums «hablan» a los Espíritus en este estado de conciencia modificado. La medicina espiritista y sus médicos no pueden, pues, sino oponerse a la interpretación hospitalaria y patológica. Para los médicos espiritistas las médiums no son ni histéricas, ni locas: están sanas. En la Revue spirite se afirma que la hipnosis debe estudiarse sobre sujetos sanos; «si insistimos sobre este punto, es porque se ha abusado en exceso de la Salpêtrière para hacer experiencias hipnóticas muy curiosas, muy recreativas, pero nada científicas ${ }^{26}$. Si bien en un primer momento los espiritistas estaban interesados en los trabajos de Charcot, muy pronto se rebelan contra las posiciones del neurólogo. En mayo de 1881, la Revue spirite, a través de la pluma de Charles Fauvéty, acusa a Pierre Régnard, colaborador de Charcot, de mala fe por negarse a hablar de magnetismo animal, «asunto prohibido a todos los que pretenden hacer carrera». Les indigna que a la pregunta «¿qué es el magnetismo animal?», Charcot responda que no tiene ni idea, que él estudia la histeria ${ }^{27}$. Sin embargo, son conscientes de la visibilidad que Charcot ha dado al magnetismo. «M. Charcot ha ampliado mucho el dominio del magnetismo que, bajo el nombre de hipnotismo, ha entrado ya en la ciencia»; pero le reprochan su deliberado rechazo a situarse en la línea del magnetismo «cuyo nombre este sabio profesor se abstiene de pronunciar ${ }^{28}$. Además, en tanto que representante de la ciencia oficial, le acusan de haber iniciado la confusión entre el magnetismo y «los fenómenos patológicos que [la ciencia oficial] clasifica bajo el nombre de hipnotismo en personas histéricas ${ }^{29}$. Para muchos espiritistas, las experiencias de Charcot ponen de manifiesto simples fenómenos asociados a una acción fluídica, y cuando se crea la Societé de Psychologie physiologique de París en torno a Charcot, Théodule Ribot, Charles Richet y Pierre Janet, los espiritistas comparan esta iniciativa a la de los científicos ingleses inaugurando la Society for Psychical Research ${ }^{30}$. Pero se equivocan...

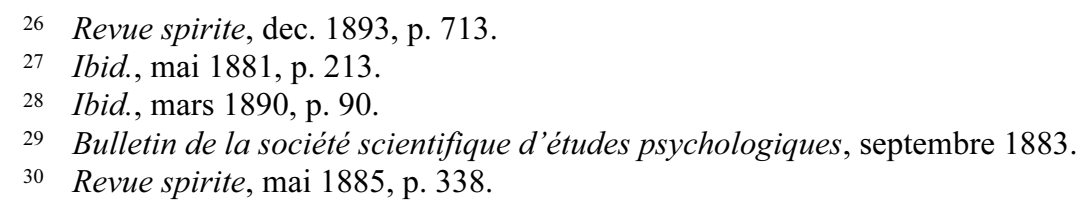


Mientras que el antagonismo con el neurólogo Jean Martin Charcot es absoluto, el médico Gérad d'Encausse ${ }^{31}$ (1865-1916), jefe del laboratorio de hipnoterapia de la Charité, asociado al Dr. Jules Luys, médico especializado en trabajos sobre la hipnosis, el sistema nervioso y las funciones cerebrales, puede parecer, por el contrario, más próximo a los espiritistas. Encausse es, en efecto, más conocido por su nombre de ocultista, Papus. Próximo, primero, a los teósofos y a Héléna Blavatsky, se aleja luego de ellos y se independiza dirigiendo la revista L'initiation, cuyo primer número aparece en octubre de 188832. Crea luego Le Voile d'Isis y la Orden martinista. A sus conocimientos médicos y ocultistas añade los de los orígenes mesmeriano y puyseguriano del hipnotismo. A menudo viaja a Nancy para encontrarse con Stanislas de Guaita (1861-1897)33 y allí descubre la fama del médico magnetizador $\mathrm{Au}-$ guste Liebéault, del que admira las terapéuticas magnéticas y el libro $D u$ sommeil et des états analogues considérés surtout du point de vue de l'action du moral sur le physique, publicado en 1866. Para él, este médico de pobres reconcilia lo antiguo y lo moderno, lo fluídico y lo psicológico. Gérard d'Encausse, basándose en su trabajo en el hospital de La Charité, muestra también cómo la hipnosis y sus derivados pueden emplearse con el objeto de curar algunas afecciones nerviosas hasta entonces rebeldes a todos los tratamientos habituales. Sus experiencias le permiten, en particular, exponer de manera ejemplar las dificultades de experimentar sobre seres humanos, lo que constituye uno de los principales obstáculos de las experiencias espiritistas: «En el hipnotismo (...) los aparatos de verificación no son ya instrumentos físicos; más bien se trata de seres humanos situados por la hipnosis en condiciones particulares de excitabilidad» ${ }^{34}$. Resume así las tres condiciones para experimentar con pertinencia y fiabilidad: 1) estar muy habituado a la experimentación hipnótica, lo que permite paliar las mentiras, las simulaciones de los sujetos, y observar los hechos; 2) multiplicar los sujetos empleados: un solo sujeto no da más que una hipótesis; y sobre todo, 3) evitar los «sujetos que se dicen profesionales», pues las investigaciones no deben realizarse más que

31 G. Encausse defiende su tesis de medicina en 1894. Se titula: L'Anatomie philosophique et ses divisions, augmentée d'un essai de classification méthodique des sciences anatomiques.

32 Cfr. Andre, M.S.; BeaufiLs, Ch. (1995). Papus, biographie. Paris, Berg International.

33 Este poeta de Nancy fue el fundador, en el seno del martinismo, de la Orden cabalística de la Rosa-Cruz, especie de círculo interior de dirección. Cfr. Laurant, J.P. (1993), L'ésoterisme, Paris, Cerf, pp. 49-50.

34 D'EnCAusse, G. (1893). De l'expérimentation dans l'étude de l'hypnotisme. A propos des prétendues expériences de contrôle de M. Hart de Londres. Clermont (Oise), Saint André, p. 1 (En Annales de psychiatrie et d'Hypnologie, fevrier 1893). 
sobre sujetos hipnotizables que nunca antes hayan sido utilizados para investigaciones análogas. «Como resultado de los trabajos de las escuelas hipnóticas se ha creado en París - escribe - una profesión nueva que ha hecho más daño a estos estudios que todos los ataques y las polémicas precedentes: la profesión de 'sujeto hipnótico'. Un sujeto que se dice profesional, que por algunos francos se exhibe sobre los escenarios o 'hace los salones' es un aparato tan peligroso como poco sensible» ${ }^{35}$.

Gérard d'Encausse, sumergiéndose cada vez más en el ocultismo, se autoriza a proponer un recorrido teórico sincrético formulando en particular las conexiones entre la corriente ocultista y la medicina. Como los espiritistas, concibe un hombre compuesto por tres principios: 1) el espíritu o alma; 2) el cuerpo físico, formado por células materiales y perecederas, y por fin 3) el cuerpo astral, que hace funcionar automáticamente ciertos órganos del cuerpo y que vincula el cuerpo al espíritu. A la muerte del cuerpo físico, los principios inferiores puramente mecánicos del cuerpo astral permanecen en la tierra; denominados «elementales», son a menudo confundidos con Espíritus por los espiritistas. A cambio, los principios superiores portan el espíritu, que sólo raramente y con dificultades puede ser invocado. Sin duda a causa de sus conocimientos médicos, Encausse estima que condición de médium e hipnosis proceden de un mismo principio y asocia de buen grado a los médiums espiritistas con los histéricos ${ }^{36}$. Retomando la clasificación de los tres estados hipnóticos de Charcot, afirma que en el primer estado hipnótico, el de la letargia, el médium puede separar su cuerpo astral de su cuerpo físico, y su sueño es profundo; en el segundo, la catalepsia, es posible el éxtasis; en el tercero, el sonambulismo lúcido, el cuerpo astral se evade y puede viajar en el espacio y en el tiempo: la clarividencia puede, entonces, existir; el médium ve, predice, cura, pero siempre por sí mismo, sin necesidad de Espíritus. Así, Gérard Encausse concibe la posibilidad de un inconsciente, lo que irrita a los espiritistas. Además, según su concepción, la parte práctica de la ciencia ocultista es la magia, y esta ciencia se esfuerza, «partiendo de los hechos físicos, por elevarse hasta el estudio de la parte invisible, oculta, de la Naturaleza y del Hombre: de aquí su primera característica de «Ciencia de lo escondido» ${ }^{37}$.

35 Ibid., p. 3.

36 Sigue las clasificaciones de J.M. Charcot y J. Luys, según las cuales la hipnosis es una histeria experimental.

37 Papus (Dr. G. Encausse) (1929) Qu'est-ce que l'occultisme? Suivi de Pourquoi nous sommes sur terre? Et de L'Astral des coses. Reed. Liège, Librairie des sciences physiques Leymarie, p. 17. 
Esta doble noción, de escondido y de mágico, sitúa de forma clara a este médico al margen de los espiritistas, quienes se proclaman, por el contrario, próximos a los científicos, que viven y experimentan al descubierto. Así pues, los espiritistas van a combatir solos.

Para ellos los médiums no solamente no son histéricos, sino que el espiritismo en sí, gracias a la acción de los espíritus, es una terapéutica. En 1883 el Dr. Chazarain, médico espiritista, presenta el espiritismo como el cuidado de eso que los «psychiâtres» (sic) llaman enfermedades mentales. Afirma que la unión de ciencia y espiritismo será «la señal de un gran progreso para la etiología y la terapéutica de las neurosis y de las enfermedades mentales hasta ahora mal comprendidas y demasiado a menudo consideradas incurables. Ya adivinan ustedes que hablo de ciertos estados erróneamente atribuidos a la histeria, a esos desdoblamientos de personalidad, inexplicables para la ciencia oficial, y que no son sino encarnaciones y posesiones $\rangle^{38}$. Para mostrar la eficacia de la intervención de los espíritus, se presentan diversos ejemplos de curación en las revistas y los boletines espiritistas, y se invita a los médicos a comprobarlos.

Los médicos espiritistas parecen tomar por modelo a los médicos católicos. En efecto, los videntes católicos de ambos sexos fueron sistemáticamente observados: Bernadette Soubirous ${ }^{39}$ fue sometida a las miradas clínicas y críticas de escépticos y de creyentes ${ }^{40}$. Los periódicos locales y regionales hablaban de catalepsia y de éxtasis, el comisario cantonal de policía de «alucinación», y el procurador general la consideraba «afecta de una enfermedad mental conocida ${ }^{41}$. También tres médicos fueron convocados para dictaminar sobre su estado a finales del mes de marzo (la primera aparición había tenido lugar el 11 de febrero de 1858). Bernadette Soubirous «tiene un temperamento linfático y nervioso», pero nunca ha sufrido «crisis nerviosas», $\mathrm{y}$ «ha podido presentar un estado extático que se ha renovado muchas veces, y ésta es una afección moral cuyos efectos explican el fenómeno de la visión» ${ }^{42}$. Los cuatro niños que dijeron haber visto a María en el cielo de Pontmain (Mayenne, cerca del Mont Saint Michel), el 17 de enero de 1871, fueron también sospechosos de sufrir alucinaciones, diagnóstico postulado por los tres médi-

38 Bulletin de la société scientifique d'études psychologiques, mars 1883.

39 Se trata de la niña que dijo haber visto a la Virgen María en Lourdes (N. del T.)

40 HARRIS, R. (2001). Lourdes, la grande histoire des apparitions, des pélérinages et des guérissons. Paris, J.C. Lattès ( $1^{\mathrm{a}}$ ed. Lourdes, Body and spirit in the secular age. Allen Lane, The Penguin Press, 1999).

41 Laurentin, R. (1957). Lourdes, dossier des documents authentiques, $t$. 1.. Paris, Lethielleux, pp. 159-187.

42 Ibid., p. 258. 
cos que los examinaron en diciembre ${ }^{43}$. Los milagros de Lourdes fueron sistemáticamente contestados. La primera curación tenida por milagrosa data del primero de marzo de 1858, pero hasta el 18 de enero de 1862, fecha de una carta pastoral de Monseñor Laurence que reconoce la autenticidad de las apariciones, la Iglesia mantuvo su reserva frente a estos fenómenos, aunque existieran controles espontáneos hechos por el Dr. Dozous, de Tarbes, y luego por el Dr. Vergez. Su sucesor, el barón Dunot de Saint Maclou, fue médico residente desde 1884 hasta su muerte en 1891. "Creía apasionadamente en la intervención de lo sobrenatural en los asuntos humanos, pero desconfiaba también de los peligros del entusiasmo e insistía en la necesidad de un certificado médico para atestiguar sobre el estado previo del peregrino» ${ }^{44}$. Así pues, intentó dar un cierto rigor a los procedimientos de examen de las curaciones milagrosas y organizó una «Oficina de comprobaciones médicas». A su muerte, el Dr. Gustave Boissaire asumió su dirección hasta 1917 y le dio una gran importancia, invitando a acudir a sus colegas. Gran número de médicos lo harán, muchos por simple curiosidad científica. De algún modo, la creencia en la eficacia de la intervención mariana remite a la de los espíritus.

In fine, pueden resumirse las certidumbres de los espiritistas siguiendo las palabras pronunciadas por el Dr. Chazarain con ocasión del banquete anual de la sociedad de estudios psicológicos en 1883: «Afirmo, con la convicción que da la observación clínica, que la iniciación espiritista cura a los pretendidamente alucinados dándoles la explicación y la prueba de la realidad de sus sensaciones y los medios de hacerlas cesar si son demasiado penosas para ellos. Digo pues que la medicina obtendrá del conocimiento del espiritismo ventajas al menos iguales, si no superiores a las que le ha dado el estudio del magnetismo; y del mismo modo que el magnetismo, negado primero y luego rechazado por los sabios que no veían en él más que un nuevo modo de charlatanismo, y estudiado, comprendido y explicado luego, convertido al fin en científico, se ha impuesto a su espíritu como una rama del arte de curar al mismo título que la electricidad; del mismo modo, el espiritismo, que en una de sus divisiones, no es sino un magnetismo especial, el magnetismo de los invisibles (todos los médiums se ven magnetizados por ellos) se impondrá a su vez desde que los fenómenos espiritistas sean reconocidos como posibles, a partir de los conocimientos ya adquiridos, al tener una gran analogía con los

43 Sin embargo, se sabe que en 1920 Jeanne-Marie Lebossé (1861-1933), una de los tres pequeños, se retractó afirmando que no había visto a «la hermosa señora».

44 HARRIS, R. (2001), p. 438. 
fenómenos del magnetismo y con algunos hechos puestos de relieve por estudios físicos, químicos y biológicos» $\rangle^{4}$.

Frente a las interpretaciones de los médicos psiquiatras y de los psicólogos interesados en los fenómenos mediúmnicos, los espiritistas oponen sistemáticamente su convicción de una intervención de los Espíritus, lo que no les impide por otra parte ser a menudo muy lúcidos respecto a ciertas nosologías psiquiátricas y ciertas normas sociales: «Es la sociedad — escriben-quien en parte hace sus locos, sus enfermos y sus criminales (...) Según la época o el lugar la locura cambia de nombre y de caracteres» ${ }^{46}$.

A finales de siglo siguen muy de cerca los trabajos que el médico y filósofo ginebrino Théodore Flournoy (1854-1920) realiza con su médium Elise Müller (1861-1929), alias Hélène Smith. En estado de sonambulismo ésta dice hablar el sánscrito, el marciano y el ultramarciano, lenguas del planeta Marte. Pretendía haber sido también una princesa india, y tener por guía a un cierto Léopold, alias Cagliostro. Th. Flournoy analizó de forma extensa los poderes psíquicos particulares de esta mujer en la obra Des Indes au planète Mars $^{47}$, publicada en 1900. Fue uno de los descubridores de las capacidades de ese inconsciente que Freud traía a la luz en el mismo momento, pues Die Traumdeutung aparece también en 1900. ¿Qué dicen al respecto los espiritistas? «Hipótesis por hipótesis, la nuestra nos parece más lógica y mejor adaptada a los hechos que la del psicólogo ginebrino» ${ }^{48}$. ¿No es, en efecto, más fácil creer en los espíritus que en ese inconsciente que se escondería, en ese yo desconocido que podría actuar sin nosotros saberlo? En efecto, a los espiritistas (como sin duda a mucha gente) les resulta impensable que pueda existir una disociación en el seno del yo. ¿No es más lógica la explicación por la toma de posesión de un cuerpo por un Espíritu? «Así pues, parece racional admitir como absolutamente verdadero el fenómeno de la encarnación en los órganos del médium de espíritus a veces superiores que se sirven de estos órganos para producir manifestaciones de las que los científicos pueden aprovecharse tanto como nosotros $\gg^{49}$. Los espiritistas distinguen cuidadosamente el estado de sonambulismo magnético, que sería debido al fluido nervioso del magnetizador actuando sobre el cerebro del magnetizado, de la condición de médium, fenó-

45 Dr Chazarain, discurso leido en el banquete anual de la Société des études psychologiques, «Le spiritisme et la science». En: Le spiritisme. Organe de l'union spirite française, 1, p. 45.

46 Revue spirite (1886), p. 238.

47 Publicado en 1983 por Le Seuil.

48 Revue scientifique et morale du spiritisme, mai 1902, p. 649.

49 Revue spirite, juin 1883, p. 267, 
meno debido al desprendimiento del alma o a la penetración de un espíritu que toma posesión del médium. Lo que los médicos llaman «inconsciente», ellos lo llaman simplemente «Espíritu». Afirman, pues, sin vacilación que «el tiempo de la creencia ciega ha pasado: hoy es necesario, para que una teoría filosófica, moral o religiosa sea aceptada, que repose sobre el fundamento inquebrantable de la demostración científica (...) El gran poder del espiritismo consiste en la libertad de examen que deja a sus adeptos» ${ }^{50}$.

Las reacciones de los médicos no espiritistas, ya sean neurólogos, alienistas o generalistas, son, en conjunto, muy críticas. No sólo denuncian la ineficacia de esas prácticas, sino que muestran su peligrosidad. Para Jean Martin Charcot y muchos de sus colegas, el espiritismo es una causa de histeria, y para los alienistas provoca la alienación mental. Desde los comienzos del espiritismo, el alienista Louis Calmeil (1798-1895) teme que «nuevos errores amenacen todavía a la patología mental. Y es del magnetismo y del espiritismo de donde comienzan a derivar estas epidemias de disolución de la personalidad de las que América ha dado los primeros y recientes ejemplos» ${ }^{51}$. En 1863 el médico Philippe Burlet escribe un libro titulado Du spiritisme considéré comme cause d'aliénation mentale. En él se levanta contra las prácticas espiritistas: «Desde hace algunos años, el hospicio de l'Antiquaille de Lyon y los demás establecimientos especiales del departamento del Ródano han dado asilo a gran número de desdichados que se han vuelto locos por haber intentado adquirir el poder de comunicar con los espíritus $\rangle^{52}$. Estas acusaciones no cesarán y darán lugar a la publicación de muchas obras ${ }^{53}$. A finales del siglo XIX, los alienistas señalan que numerosos enfermos se creen perseguidos por la electricidad, los rayos $\mathrm{X}$ y los espíritus que se anuncian por medio de golpes... que sustituyen ventajosamente al diablo.

50 Delanne, G. (1897). Le phénomène spirite, témoignage des savants. Paris, Chamuel (5 $5^{\mathrm{a}}$ ed.). p. 285.

51 Citado en: Drs. MARIE et Viollet (1904) «Spiritisme et folie». En: JANET, P.; DuMAS, A. (Dirs.) Journal de psychologie normale et pathologique, juillet-août, p. 2. Marcel Viollet, medico de los asilos, escribió L'espiritisme dans ses rapports avec la folie (Paris, Bloud, 1908).

52 Philippe Burlet, antiguo interno de los hospitales de Lyon (1863). Du spiritisme considéré comme cause d'aliénation. Lyon, Richard, p. 11.

53 Sobre éste tema véase Le Malefan, P. (1999). Folie et spiritisme. Histoire du discours psychopathologique sur la pratique du spiritisme, ses abords, et ses avatars (18501950). Paris, L'Harmattan. 
DEMOSTRAR EL PERIESPÍRITU.

En este marco de conflicto, demostrar la existencia de los espíritus y del periespíritu parece desde luego esencial para validar las terapéuticas espiritistas. Desde la muerte de Kardec, el 2 de abril de 1869, el astrónomo Camille Flammarion, al hacer el elogio del difunto, anuncia que, en adelante, el espiritismo debe «entrar en su período científico» ${ }^{54}$. Afirma que «el espiritismo no es una religión, sino una ciencia, de la que apenas conocemos el a b c (...) La ciencia física nos enseña que vivimos en medio de un mundo invisible para nosotros, y que no es imposible que seres (igualmente invisibles para nosotros) vivan igualmente sobre la tierra en un orden de sensaciones absolutamente diferente del nuestro» ${ }^{55}$. Afirma también que el cuerpo no es más que «un ensamblaje transitorio de partículas que no le pertenecen en absoluto y que el alma ha agrupado según el tipo que le es propio para crearse los órganos que puedan ponerla en relación con nuestro mundo físico» ${ }^{56}$.

Las primeras demostraciones espiritistas se apoyarán sobre la fotografía, cuyo papel en la medicina es, en ese momento, también importante, siendo utilizada por los médicos de hospital, como D.M. Bourneville, J.M. Charcot o J. Luys, como testimonio y prueba de ciertos fenómenos, que acentúa y precisa la mirada clínica. Este primer intento espiritista es un fiasco. Sin embrago, los espiritualistas de Estados Unidos habían lanzado, con éxito, la foto espectral ${ }^{57}$, y siguiendo su ejemplo P.G. Leymarie, director de la Revue spirite desde la muerte de Kardec, había adquirido ejemplares de tales fotos para su periódico. La reproducción de estas fotos espectrales se confió a Jean Buget, quien pronto se declaró capaz de hacerlas él mismo. Cubierto primero de elogios por los compradores, pues cada cual reconocía a sus difuntos en las fotos, fue pronto acusado de fraude y sus malversaciones fueron descubiertas en 1875. Pero su fracaso, atribuido a la falta de probidad, no puso en cuestión la veracidad de la existencia del periespíritu. Muy al contrario, los espiritistas crearon otros marcos de estudio para proseguir sus experiencias.

En junio de 1878 vio la luz una Société scientifique d'études psychologiques, bajo el impulso entre otros de René Caillé, Charles Fauvéty, Eugene

54 Flammarion, C. (1978). «Discours pronnoncé aux obsèques d'Allan Kardec». En: KARDEC, A. Oeuvres posthumes, Paris, Dervy, p. XXXIII.

55 Ibid., p. XXXIV.

56 Ibid., p. XXXVIII.

57 Véase el catálogo de la exposición Le Troisième oeil, la photographie et l'occulte. Paris, Gallimard, 2004. 
Nus y el barón Jules du Potet de Sennevoy (1796-1881). Esta vieja figura del magnetismo, uno de los defensores de la teoría fluidista, constituye el nexo, que apenas es preciso recalcar, con el magnetismo. Esta filiación tiene como resultado que las experiencias de los espiritistas entren en el índice del mundo científico, ya que hace dudar acerca de la credibilidad del conjunto de tales observadores. Sin embargo, esta sociedad proclama sus intenciones científicas; tiene «por objeto el estudio de todas las ciencias que se relacionan con la psicología (...) Se consagrarán sesiones al estudio de las leyes de orden moral y de los fenómenos espiritualistas (...) Una sociedad seria, dirigida por hombres entregados a las investigaciones científicas, es la única que puede constituir estas sesiones de observación y hacer que progresen las cuestiones filosóficas (...) Las damas pueden ser miembros de la sociedad $\rangle^{58}$. Si los espiritistas utilizan el término psicología es porque reprochan «a las sociedades psíquicas no tener por objeto demostrar experimentalmente la existencia y la supervivencia del alma después de la muerte, y no preocuparse más que de establecer los hechos sin adelantar interpretación alguna sobre su naturaleza supranormal» ${ }^{59}$. Para ellos se trata, a la vez, de desmarcarse de las investigaciones más fecundas que los anglosajones llevan a cabo en las Societies for Psychical Research creadas a comienzos de los años 1880 y que apuntan, entre otras cosas, a demostrar la existencia de un nuevo estado de la materia, y de apoyarse sobre sus resultados para interpretarlos a su manera. "Adquirir la prueba de esas fuerzas desconocidas ofrece el mayor interés a quien pretenda hacer una investigación científica del alma y de las manifestaciones psíquicas» ${ }^{60}$, se lee en La revue spirite. Cuando el gran químico inglés William Crookes parece haber descubierto un nuevo estado de la materia del que habla en febrero de 1880, en una conferencia en la Facultad de Medicina de París, los espiritistas piensan que esta «materia radiante» se confundiría con la materia que constituiría el periespíritu.

Sin embargo, si los trabajos de este científico son importantes, no pueden satisfacer plenamente a los espiritistas. W. Crookes admite la existencia de una fuerza física, rechazando los postulados de aquellos. «La diferencia entre los partidarios de la Fuerza psíquica y los espiritualistas consiste en que nosotros nos contentamos con afirmar que aún sólo existen pruebas muy insuficientes que establezcan un agente de dirección diferente de la inteligencia del médium, y que no existe ninguna prueba de la intervención de los Espíritus de

\footnotetext{
58 Revue spirite, juin 1878, pp. 228-229.

59 Plas, R. (2000), p. 26.

60 Revue spirite, juin 1878, p. 367.
} 
los muertos» ${ }^{61}$. El 29 de enero de 1897, en un discurso ante la Society for Psychical Research inglesa de la que es presidente, Crookes afirma que la criatura humana no es sino una forma en el interior de la cual lo importante es el cerebro: «para comunicar con el mundo exterior, el cerebro tiene necesidad de órganos que le transporten de un lugar a otro, luego de otros órganos que suministren la energía necesaria para reemplazar la que el propio cerebro gasta en el ejercicio de sus funciones especiales (...) El ser humano representa la máquina de pensar y de trabajar más perfecta que hasta el presente haya evolucionado sobre nuestra tierra $»^{62}$. Su forma ha podido variar en el curso del tiempo: «No puedo dejar de creer - dice - que la Materia, la Forma, el Espacio sólo sean condiciones temporales de la vida presente. Es difícil concebir seres espirituales que tengan un cuerpo como el nuestro, condicionado por la atracción terrestre, con órganos que impliquen la necesidad de nutrirse y de evacuar las materias usadas. Igualmente difícil es, encerrados como estamos en las ideas del mundo material, concebir la Inteligencia, el Pensamiento, la Voluntad, existiendo fuera de la forma y de la materia así como de la gravedad y del espacio» ${ }^{63}$. Para él «este ser sería un centro de inteligencia, de voluntad y de energía que podría penetrar a todos los demás, llenando por completo lo que llamamos espacio, siempre conservando su individualidad propia, la persistencia de su yo y su propia memoria» ${ }^{64}$. Se plantea la transmisión de pensamiento como ciertas «vibraciones cuyas huellas seguimos, no sólo en los cuerpos sólidos, sino también en el aire y de una manera aún más notable en el éter», o bien como cierta irradiación: «Supongamos, además, que el cerebro contiene un centro que los genera [a los rayos] como las cuerdas vocales generan las vibraciones vocales a las órdenes del pensamiento, y los proyectan al exterior a la velocidad de la luz para ir a impresionar el ganglio receptor de otro cerebro» ${ }^{65}$.

En 1898 postula la que cree ser «una ley fundamental: que los pensamientos y las imágenes pueden ser transportadas de un espíritu a otro sin el socorro de los órganos de los sentidos; que los conocimientos pueden penetrar en el espíritu humano sin pasar por ninguno de los caminos hasta hoy conocidos (...) Cada nuevo progreso de la ciencia nos demuestra que las vibraciones del

61 Crookes, W. (1874). Notes sur des recherches faites dans le domaine des phénomènes appelés spirites pendant les années 1870-1873, publiées par le Quarterly Journal of Science.Paris, Librairie Spirite, p. 28.

62 Crookes, W. (1903). Discours récents sur les recherches psychiques. Paris, P.G. Leymarie, p. 10.

63 Ibid., p. 15.

64 Ibid., p. 16.

65 Ibid., pp. 28 y 32. 
éter tienen poderes y cualidades ampliamente suficientes para dar cuenta de todo, incluso de la transmisión del pensamiento» ${ }^{66}$.

Sin embargo, recuerda también el éxito de curas por sugestión realizadas por médicos como Liébeault, Bernheim, Schrenck-Notzing, Forel o Auguste Voisin. Hace referencia a los trabajos de Richet, de Janet, de Freud, de Breuer, de James, sobre las zonas de la infraconsciencia, el subconsciente o el inconsciente. $\mathrm{Y}$ en ese punto se encuentra, y de forma violenta, en oposición a los espiritistas, que continuarán solos sus investigaciones.

La Société scientifique d'études psychologiques, en la sección de magnetismo, centrará estos experimentos esencialmente en los fenómenos de transmisión de pensamiento y lucidez ${ }^{67}$. Magnetizadores y sonámbulos multiplican los experimentos de sugestión, de éxtasis o de catalepsia... lo que en el mismo momento están haciendo Luys y Charcot en la Charité y la Salpêtrière, aunque desde luego no con las mismas hipótesis, ni con los mismos objetivos. En diciembre de 1882, Le Spiritisme, organe de l'union spirite française creado en torno al ingeniero Gabriel Delanne (1857-1926), que se presenta como científico, mantiene la misma orientación experimental que sostendrá luego la Revue scientifique et morale du spiritisme, cuyo primer número aparece en julio de 1896. Delanne reafirma en ella la existencia del periespíritu y se apoya en las pruebas que estima aportadas ya por la fotografía o por las huellas que los Espíritus dejarían en la arcilla fresca empleada a tal efecto. Este periespíritu es para él «el receptáculo indestructible de todas las sensaciones» que conserva la inteligencia, la memoria y permite explicar el recuerdo después de la muerte ${ }^{68}$. El 7 de octubre de 1890 el espiritista Laurent du Faget crea a su vez una Société du spiritisme scientifique, proclamando siempre los mismos objetivos: «verificar y hacer verificar los hechos espiritistas, probar que hay inteligencias que se comunican con nosotros desde el otro lado de la tumba» ${ }^{69}$.

Frente a los médicos que exploran el inconsciente y traen a la luz la complejidad del yo, los espiritistas, convencidos de estar en posesión de la verdad, continúan su lucha y reivindican en voz alta el carácter científico de su proceder. Con ocasión de diferentes congresos debaten y afinan sus argumentos. Así se celebra, en 1888, un primer Congreso espiritista y espiritualista

66 Crookes, W. (1903). «Fragment du discours prononcé en 1898 à Bristol au Congrès de l'Association britannique pour l'avancement des sciences». Op. cit, pp. 40-41.

67 «Lucidité» en el original. Se corresponde con la idea de «extralucidez», implícita en el concepto parapsícológico de «percepción extralúcida» (N. del T.)

68 Le spiritisme, organe de l'union spirite française, janvier 1892, p. 2.

69 Revue spirite, novembre 1890, p. 507. 
internacional en Barcelona, y luego un segundo, en 1889, en el marco de las conmemoraciones del centenario de la Revolución Francesa en París, que reúne cerca de 500 delegados llegados del mundo entero. Espiritistas, teósofos, martinistas y rosacruces están en él representados. A imagen del centenario de 1789, los objetivos del congreso son universalistas: ¡voluntad de solidaridad y de justicia entre todos los seres humanos, comprendidas las mujeres! No se olvida el dominio científico, y se recuerda que el espiritismo «es una ciencia de observación y una doctrina filosófica (...) una ciencia que trata de la naturaleza, del origen y del destino de los espíritus, (...) de un estado de sustancia particular que es inteligente $\rangle^{70}$. Se debate la persistencia del yo consciente después de la muerte, se reafirma que magnetismo y espiritismo están íntimamente vinculados, siendo el magnetismo el espiritismo de los vivos y el espiritismo el magnetismo de los muertos, y se subrayan los lazos entre hipnotismo y espiritismo. Los congresistas consideran que el hipnotismo conduce al espiritismo porque permite la ocupación del cerebro hipnotizado por los Espíritus: «es una verdadera sugestión que no es producida por uno de nosotros, sino por inteligencias invisibles $\rangle^{71}$. Los espiritistas distinguen netamente sus dos grandes estrategias terapéuticas: la acción de los Espíritus y el magnetismo, concebido como un mero agente físico. En los congresos sucesivos se registran escisiones y nuevos reagrupamientos; en 1900 tiene lugar en París un Congreso Espiritista y Espiritualista Internacional, y el mismo año los espiritistas solos organizan un Congreso Espiritista Universal en Bruselas, y en 1913 en Ginebra. Se apropian de buen grado de los descubrimientos médicos o los reinterpretan. Así, en las actas del Congreso de 1913 puede leerse, de la pluma del espiritista Léon Denis: «algo que todos conocéis, pero que es preciso recordar, es que el espiritismo no es ajeno a toda la serie de descubrimientos que se han sucedido desde hace treinta años, cuarenta años, y que han producido una auténtica revolución en el campo de la física y de la química. Sabéis que ha sido observando la materialización de los espíritus, estudiando el trabajo de la sustancia en acción en el punto en que se transforma en energía, como ha nacido la primera idea de la materia radiante. Y de aquí, toda la serie de descubrimientos de las fuerzas radiantes, de la radiactividad de los cuerpos $>72$.

Sus declaraciones, y aún más sus prácticas, fueron, en efecto, objeto de múltiples y atentas observaciones médicas. Se sabe hasta qué punto la exis-

70 Congrès Spirite et Spiritualiste International de 1889, tenu à Paris du 9 au 16 septembre1889. Paris, Librairie spirite, 1890, p. 3

71 Ibid., p. 9

72 2ème Congrès spirite universel, Genève 1913. Informe estenográfico, p. 8. 
tencia de médiums fue importante para que la psicología se constituyera en tanto que ciencia humana y para que el inconsciente fuera descubierto. Por otra parte, en este final del siglo XIX numerosos científicos, médicos, físcos, químicos, astrónomos, no rechazan la posibilidad de la existencia de un estado desconocido de la materia, como acabamos de ver, ni la supervivencia del «espíritu» humano después de la muerte. Y no olvidemos que una gran parte de la población europea y norteamericana es cristiana. Cree, pues, en la supervivencia del alma, y estas décadas son, además, las del apogeo de la creencia en el purgatorio en Francia ${ }^{73}$. Por ello no es absolutamente extraño que los espiritistas participen en el IV Congreso Internacional de Psicología que se celebra en París en 1900 en la sección «Psicología del hipnotismo, de la sugestión y de las cuestiones relacionadas». Léon Denis aporta a esta sección una contribución que titula Psicología experimental. Fenómenos de exteriorización y de desdoblamiento. Desde luego algunos, como el psicólogo berlinés Oskar Vogt, se rebelan contra esta presencia: «Son algunas comunicaciones inesperadas presentadas a esta sesión lo que me decide a tomar la palabra. La tomo para protestar contra el espiritismo. Protesto, en primer lugar, en nombre de la ciencia y de la psicología en general. Protesto luego especialmente en nombre de la ciencia de la sugestión y del hipnotismo. Apenas hemos conseguido hacer que se reconozca la realidad de la sugestión y del hipnotismo, apenas hemos llegado a inaugurar, partiendo de estos fenómenos, una psicopatogenia, una psicoterapia y una psicohigiene en un sentido más amplio, cuando los espiritistas invaden nuestra sección y la comprometen con comunicaciones anticientíficas $\rangle^{74}$.

Los espiritistas están aún presentes y activos en el $2^{\circ}$ Congreso Internacional de Psicología en 1913, organizado esta vez, en todo caso, por la Sociedad Magnética de Francia. En él las comisiones trabajan en temas caros a los espiritistas (y a los investigadores de las Societies for Psychical Research): fuerzas desconocidas emitidas por el hombre, conductibilidad de la fuerza física, estudio del desdoblamiento experimental del cuerpo humano y estudio del determinismo cósmico de los hechos psíquicos.

Esta búsqueda de una prueba de la supervivencia del alma y de un más allá habitado no ha cesado a lo largo del siglo XX, y el atractivo de lo oculto ha conocido pocos desfallecimientos. En la Belle époque, el cronista del Echo de Paris ironizaba: «el espiritismo, como el socialismo, como el automovilismo,

73 Cfr. Cuchet, G. (2005). Le crépuscule du purgatoire. Paris, Armand Collin.

74 Vogt, O. «Contre le spiritisme». IV $V^{\text {ème }}$ Congrès de Psychologie (Paris, 20-26 août 1900). Paris, Alcan, p. 656. Cit en: PLAS, R. (2000), p. 36. 
cada vez está más de moda. Estamos lejos de aquél tiempo en que esta semiciencia parecía temible y complicada (...) Hoy es más fácil obtener la comunicación con el más allá que por teléfono» ${ }^{75}$. Aunque hoy las comunicaciones telefónicas hayan mejorado mucho, también se han renovado las comunicaciones con el más allá. Lejos de petrificarse, el espiritismo, una forma de lo oculto, sigue en movimiento y las sociedades espiritistas están bien vivas y activas en el mundo entero. Sus concepciones médicas evolucionan al ritmo de los descubrimientos neurológicos y psiquiátricos. Su fuerza reposa sin duda en la unión de esta capacidad de integración de los hechos científicos y su creencia en la intervención posible de Espíritus venidos de otra parte. Así, lo oculto «no es una forma de lo irracional, sino una participación activa en la construcción y el mantenimiento de la frontera entre lo racional y lo irracional (...) Lejos de ser una seudociencia, el ocultismo ha aportado sin duda una de las más importantes contribuciones a la construcción histórica del discurso racionalista sobre las ciencias» ${ }^{76}$.

Fecha de recepción: 7 de junio de 2006

Fecha de aceptación: 5 de septiembre de 2006

75 L'écho de Paris, journal littéraire et politique du matin, 3 fevrier 1897.

76 Lagrange, P.; D’ANDREA, P. (1981), p. 39. 